\title{
Geochemical, Isotopic and Volumetric Signatures of Williston Basin Oil Wells Hydraulically Fractured with Crosslinked Gel
}

\author{
TANYA J. GALLEGOS ${ }^{1}$, COLIN DOOLAN ${ }^{2}$, RODNEY \\ CALDWELL ${ }^{3}$, MARK A. ENGLE ${ }^{4}$, MATTHEW VARONKA ${ }^{5}$, \\ GLENN JOLLY ${ }^{6}$, TYLER B. COPLEN ${ }^{7}$, THOMAS OLIVER ${ }^{8}$ \\ ${ }^{1}$ tgallegos@usgs.gov \\ 2 cdoolan@usgs.gov \\ 3 caldwell@usgs.gov \\ 4maengle@utep.edu \\ ${ }^{5}$ mvaronka@usgs.gov \\ ${ }^{6}$ gdjolly@usgs.gov \\ ${ }^{7}$ tbcoplen@usgs.gov \\ 8 taoliver@usgs.gov
}

Hydraulic fracturing fluids are injected into some oil and gas wells to fracture unconventional hydrocarbon reservoirs to stimulate production. Immediately after hydraulic fracturing ceases, water ("produced water") is generated at the wellhead along with oil and gas over the life of the well. The earliest water produced from the wellhead ("flowback") consists of reservoir fluids mixed with hydraulic fracturing fluid. Over time, the produced water composition transitions to that of formation fluids. Compositional fingerprinting of produced water is often used to establish the chemistry of these fluids to identify any potential contaminants found in near-surface soils, groundwater or surface water upon the inadvertent release of produced waters, stray formation fluids or hydraulic fracturing fluids. Our study measured geochemical and isotopic compositions of produced water from 17 Bakken (Middle Member) and Three Forks Formation oil wells in the Williston Basin that were hydraulically fractured with boron (B) crosss-linked gels. We applied these data to interpret the presence or absence of hydraulic fracturing fluid signatures within the produced waters. Analyzing produced water compositions in the framework of the volume of produced-to-injected waters, as an indicator of flowback fluid, the following observations were revealed: 1) $\mathrm{Ra}$ isotopes are distinct for each formation, assuming that no reuse or recycling occurred and; 2) temperature, oxygen-reduction potential, $\delta^{18} \mathrm{O}, \delta^{2} \mathrm{H}$, and $\delta^{11} \mathrm{~B}$ v. $1 /[\mathrm{B}]$ trends are distinct for flowback fluids relative to formation fluids but are more challenging to interpret because they could be influenced by both natural processes and hydraulic fracturing fluids. Use of hydraulic fracturing fluid indicators should be employed with caution because they could be influenced by recycling, reuse, on-going well maintenance and treatment activities. 